\title{
Exploring knowledge, beliefs and behaviors of parents regarding teen electronic cigarette use
}

\author{
Megan M. Weemer', Melissa A. Ketner², Sam A. Crecelius³
}

\section{Dear Editor,}

Youth e-cigarette use is a public health epidemic, prompting health professionals to investigate prevention/intervention efforts. The Social Ecological Model proposes that interventions addressing multiple levels of influence are essential to changing behavior ${ }^{1}$. The current study examined parental influences (current smoking behaviors and parenting style) as they relate to their knowledge, beliefs and behaviors surrounding teen e-cigarette use.

Odds for youth smoking increases with the number of parents who smoke 2 and e-cigarette using parents are often unaware of health risks and view e-cigarettes as a safer alternative than conventional cigarettes ${ }^{3}$. Parental antismoking expectations are associated with lower likelihood that their child will smoke and non-e-cigarette smoking youth are more likely to have parents who view e-cigarettes negatively ${ }^{4,5}$.

Positive parent-child relationships are associated with lower levels of youth smoking $^{6}$, while spending less family time together is associated with higher levels ${ }^{7}$. An authoritative parenting style and open communication between parent-child are considered protective factors ${ }^{2}$.

Data were collected electronically from a convenience sample of parents/ guardians $(\mathrm{N}=116)$ of middle and high school students in a selected Midwestern school district during Fall 2019 (IRB Approval Number: IRB-2019-512). Demographics of the sample population are included in Table 1. Guided by studies of teen alcohol use ${ }^{8}$, scales were developed to measure parent knowledge, beliefs and behaviors surrounding e-cigarettes. All items were rated on a 5 -point Likert scale ( $1=$ strongly disagree to $5=$ strongly agree). Sum scores were created for each scale by summing the item-level scores. The knowledge scale consisted of six items: electronic cigarettes contain nicotine; electronic cigarettes are just as addictive as traditional cigarettes; the smoke from electronic cigarettes is just water; electronic cigarette vapor contains harmful chemicals; electronic cigarettes may harm teen brain development; and electronic cigarettes are risk free. Possible scores ranged from 6 to 30 . The beliefs scale consisted of six items: I believe that if my child's friends use electronic cigarettes, then my child is more likely to use them as well; I believe that teens can get access to electronic cigarettes very easily; I believe that teens who use electronic cigarettes suffer negative health consequences; I believe that schools could do more to prevent electronic cigarette use among teens in our community; using electronic cigarettes, rather than traditional cigarettes, are a safe alternative for teens; and I believe that teens use electronic cigarettes to get the same 'buzz' that they get from traditional cigarettes. Possible scores ranged from 6 to 30 . The behavior scale consisted of two items: I talk to my child about the dangers of electronic cigarettes; and I enforce clear rules with my
AFFILIATION

1 Department of Health Sciences, Illinois State University, Normal, United States

2 Department of Social Work, University of Indianapolis, Indianapolis, United States 3 Diehl Consulting Group, Indianapolis, United States

\section{CORRESPONDENCE TO}

Megan M. Weemer. Department of Health Sciences, Illinois State University, Felmley Hall Room 305, Campus Box 5220, Normal, IL 61790, United States. E-mail: mmweeme@ilstu.edu

\section{KEYWORDS}

parents, prevention, adolescents, intervention, electronic cigarettes, social ecological model

Received: 13 November 2020 Revised: 22 December 2020 Accepted: 6 January 2020 
child about not using electronic cigarettes. Possible scores ranged from 2 to 10 . Relationships were examined between scores on knowledge, beliefs and behavior scales, and parents' personal tobacco use or family pro-social behaviors (eating family dinners, number of hours spent with children, and children's participation in extracurricular activities).

Parents who smoke had significantly lower knowledge scores (mean: 25.00, SD: 3.21) and behavior scores (mean: 8.29, SD: 1.49) compared to

Table 1. Demographic characteristics of participants ( $N=116)$

\begin{tabular}{|c|c|c|}
\hline Characteristics & $n$ & $\%$ \\
\hline \multicolumn{3}{|l|}{ Relation to child } \\
\hline Father & 27 & 23 \\
\hline Mother & 86 & 74 \\
\hline Other primary caregiver & 2 & 2 \\
\hline Stepmother & 1 & 1 \\
\hline \multicolumn{3}{|l|}{ Race/Ethnicity } \\
\hline Asian & 1 & 1 \\
\hline Black or African American & 1 & 1 \\
\hline Hispanic/Latino & 2 & 2 \\
\hline Native American & 1 & 1 \\
\hline Other & 4 & 3 \\
\hline White & 107 & 92 \\
\hline \multicolumn{3}{|l|}{ Marital status } \\
\hline Divorced & 12 & 10 \\
\hline Married & 96 & 83 \\
\hline Separated & 2 & 2 \\
\hline Single & 6 & 5 \\
\hline \multicolumn{3}{|l|}{ Education level } \\
\hline High school & 11 & 10 \\
\hline Some college or Associate's degree & 29 & 25 \\
\hline Bachelor's degree & 35 & 30 \\
\hline Graduate school & 40 & 35 \\
\hline \multicolumn{3}{|l|}{$\begin{array}{l}\text { Children's participation in } \\
\text { extracurricular activities }\end{array}$} \\
\hline Participants & 106 & 91 \\
\hline Non-participants & 11 & 9 \\
\hline \multicolumn{3}{|l|}{ Adult household cigarette use status } \\
\hline Non-smoker & 102 & 88 \\
\hline Smoker & 14 & 12 \\
\hline \multicolumn{3}{|c|}{ Adult household e-cigarette use status } \\
\hline Non-user & 107 & 92 \\
\hline User & 9 & 8 \\
\hline
\end{tabular}

non-smokers [mean: 27.04, SD: $2.79 ; \mathrm{t}(114)=2.53$, $\mathrm{p}=0.013, \mathrm{~d}=0.68$, two-tailed], [mean: 9.31, SD: $1.15 ; \mathrm{t}(114)=3.00, \mathrm{p}=0.003, \mathrm{~d}=0.76$, two-tailed], respectively.

A significant, positive correlation was found between number of days a family ate together weekly and scores on the behavior scale $[\mathrm{r}(114)=0.24$, $\mathrm{p}=0.01$, two-tailed]. A significant, positive correlation existed between number of hours spent together weekly and scores on the behavior scale $[\mathrm{r}(114)=0.22, \mathrm{p}=0.02$, two-tailed $]$. Parents whose children did not participate in extracurricular activities had significantly lower knowledge scores (mean: 24.00, SD: 3.88) compared to parents whose children did participate [mean: 26.99, SD: 2.72; $\mathrm{t}(114)=-2.31, \mathrm{p}=0.023, \mathrm{~d}=0.89$, two-tailed] .

Parental smoking behaviors were correlated with significantly lower knowledge and behavior scores, indicating that parents who smoke cigarettes possess inaccurate information and take less action with their children to prevent or stop e-cigarette use. Targeted educational interventions for smoking parents surrounding e-cigarette dangers exist.

Pro-social parent behaviors were significantly, positively correlated with behavior scores. The majority of parents in this study enforce clear expectations and have open discussions with their children about the dangers of e-cigarettes. Promoting pro-social parenting behaviors, encouraging open parent-child communication, and providing expectations surrounding e-cigarette use should be critical components of interventions.

\section{REFERENCES}

1. Cheney M, Gowin M, Clawson A. Using the Ecological Model to understand influences on college student vaping. J Am Coll Health. 2018;66(7):597-607. doi:10.1080/07448481.2018.1440578

2. Wilkinson A, Shete S, Prokhorov A. The moderating role of parental smoking on their children's attitudes toward smoking among a predominantly minority sample: a cross-sectional analysis. Subst Abuse Treat Prev Policy. 2008;3(1):18. doi:10.1186/1747-597X-3-18

3. Garbutt J, Miller W, Dodd S, Bobenhouse N, Sterkel R, Strunk R. Parental use of electronic cigarettes. Acad Pediatr. 2015;15(6):599-604. doi:10.1016/j.acap.2015.06.013

4. Waa A, Edwards R, Newcombe R, et al. Parental behaviours, but not parental smoking, influence current smoking and smoking susceptibility among 14 and 15 year-old children. Aust N Z J Public Health. 2011;35(6):530-536. 
doi:10.1111/j.1753-6405.2011.00772.x

5. Park E, Kwon M, Gaughan MR, Livingston J, Chang YP. Listening to adolescents: Their perceptions and information sources about e-cigarettes. J Pediatr Nurs. 2019;48:82-91. doi:10.1016/j.pedn.2019.07.010

6. Tyas S, Pederson L. Psychosocial factors related to adolescent smoking: a critical review of the literature. Tob Control. 1998;7(4):409-420. doi:10.1136/tc.7.4.409

7. Garmiene A, Zemaitiene N, Zaborskis A. Family time, parental behavior model and the initiation of smoking and alcohol use by ten-year-old children: an epidemiological study in Kaunas, Lithuania. BMC Public Health. 2006;6(1):287. doi:10.1186/1471-2458-6-287

8. Palmer S, Kalafatelis E. Parental Attitudes and Behaviours Towards Teen Drinking Survey of Parents of 12-17 Year Olds- Final Report. https://www.hpa.org.nz/sites/ default/files/imported/field_research_publication_file/ ParentalAttitudes.pdf. Published May 30, 2008. Accessed December 22, 2020.

\section{ACKNOWLEDGEMENTS}

The research presented in this article does not reflect the official policy of the NIH.

\section{CONFLICTS OF INTEREST}

The authors have completed and submitted the ICMJE Form for Disclosure of Potential Conflicts of Interest and none was reported.

\section{FUNDING}

There was no source of funding for this research.

\section{AUTHORS' CONTRIBUTIONS}

MW took lead on study conception, design, execution, data acquisition, drafting and revising the manuscript, and contributed to data analysis and interpretation. MK made significant contributions to study conception, design, execution, data acquisition, drafting and revising the manuscript and contributed to data analysis and interpretation. SC made significant contributions to study conception, design, execution, data acquisition, drafting and revising the manuscript, and took lead on data analysis and interpretation.

PROVENANCE AND PEER REVIEW

Not commissioned; internally peer reviewed. 